\title{
Robotic-assisted mediastinal surgery: the first Chinese series of 167 consecutive cases
}

\author{
Hanyue Li, Jiantao Li, Jia Huang, Yunhai Yang, Qingquan Luo \\ Shanghai Lung Tumor Clinical Medical Center, Shanghai Chest Hospital, Shanghai Jiao Tong University, Shanghai 200030, China \\ Contributions: (I) Conception and design: Q Luo, H Li; (II) Administrative support: Y Yang; (III) Provision of study materials or patients: J Li; (IV) \\ Collection and assembly of data: J Huang; (V) Data analysis and interpretation: H Li; (VI) Manuscript writing: All authors; (VII) Final approval of \\ manuscript: All authors. \\ Correspondence to: Qingquan Luo. Shanghai Lung Tumor Clinical Medical Center, Shanghai Chest Hospital, Shanghai Jiao Tong University, Shanghai \\ 200030, China. Email: luoqingquan@hotmail.com.
}

\begin{abstract}
Background: To report the first and largest series of robotic-assisted mediastinal surgeries performed in a single center by the same surgical team in mainland China.

Methods: From May 2009 to June 2017, 167 patients (100 males, 67 females), with a mean age of 50.2 years (range, 12-78 years), underwent robotic surgery for the treatment of a mediastinal mass. Data regarding the operation time, docking time, blood loss, conversion rate, morbidity, mortality and survival follow-up were collected and analyzed.

Results: The mean operation time and docking time were $70.01 \pm 29.49$ and $10.12 \pm 2.77 \mathrm{~min}$. There were 56 thymomas, 52 cysts, 17 schwannomas, 9 bronchogenic cysts, 6 thymic hyperplasias, 6 foregut cysts, 4 squamous carcinomas and 17 others. The mean drainage on the first day after operation was $122.83 \pm 107.58 \mathrm{~mL}$, and the mean post-operative drainage duration and post-operative hospital stay were 2.95 days, ranging from 1-7 days, and 4.09 days, ranging from 2-10 days, respectively. The post-operative complication rate was $3 \%$, and the conversion rate was $1.8 \%$. No perioperative mortality occurred. One patient died due to tumor recurrence.
\end{abstract}

Conclusions: Our experience indicates that this robotic surgical system is a safe and established technique for mediastinal mass resection.

Keywords: Robotic; mediastinal mass; micro-invasive mediastinal surgery

Submitted Dec 22, 2017. Accepted for publication Apr 16, 2018.

doi: $10.21037 /$ jtd.2018.04.138

View this article at: http://dx.doi.org/10.21037/jtd.2018.04.138

\section{Introduction}

In June 2000, the approval of the Da Vinci surgical system by the American FDA marked the birth of the first commercial surgical robot being applied in an operating room. There has been a surge in the number of robotic thoracic surgeries since the first report of robotic lobectomy in 2002 by Melfi et al. (1). In 2016, mainland China completed 2,119 robotic thoracic operations, and completed a total of 4,737 cases over the years, including 1,180 mediastinal mass resections. There have been many reports on the practice of robotic-assisted mediastinal surgery, which suggests that the robotic system seems ideally suited for mediastinal lesions and has satisfactory post-operative outcomes (2-5). Since our first robotic mediastinal mass resection in 2009 to June 2017, our center has performed 167 robotic mediastinal surgeries. Here, we would like to report the results of our 167 cases; this study is currently the largest retrospective single-center study in mainland China. We would also like to share our experience with the use of the da Vinci surgical system for mediastinal mass resection.

\section{Methods}

We respectively reviewed all patients who underwent 


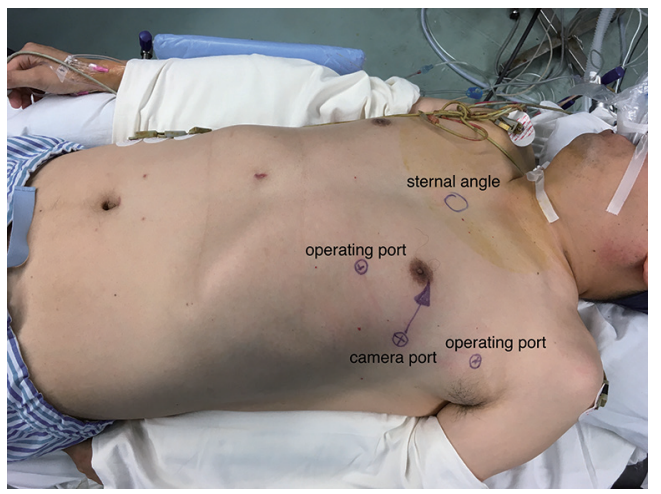

Figure 1 Patient with anterior mediastinal mass (camera port: Fifth intercostal space at the mid-clavicular line; operating ports: third intercostal space close to mid-axillary line, fifth intercostal space at the mid-clavicular line).

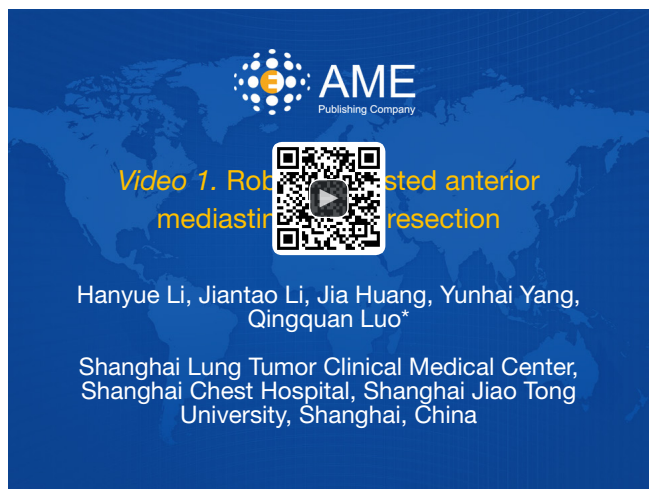

Figure 2 Robotic-assisted anterior mediastinal tumor resection (6). Available online: http://www.asvide.com/article/view/24995

mediastinal surgery performed by one surgeon (Qingquan Luo) with the da Vinci surgical system from May 2009 to June 2017 at Shanghai Lung Tumor Clinical Medical Center, Shanghai Chest Hospital, Shanghai Jiao Tong University. The perioperative outcomes and long-term follow-up are analyzed in this study. The learning curve is also characterized in this study. This study was approved by the ethics board of Shanghai Chest Hospital (KS(P)1805).

\section{Surgical technique}

All procedures were performed by the same surgeon using a three-arm robotic technique. One assistant at the bedside places the trocars connects them with the robotic arms, and then enlarges the incision to remove the specimen at the end of surgery. All patients underwent satisfactory general anesthesia with double-lumen tracheal intubation. $\mathrm{CO}_{2}$ was inflated through the camera port with $6-8 \mathrm{mmHg}$ pressure. All the specimens were taken extracorporeally using either a specimen bag or surgical glove.

\section{Anterior mediastinal lesion}

Patients with an anterior mediastinal mass are positioned with the affected side up at a 25 - to 30-degree angle. The camera port is usually at the fifth intercostal space on the anterior-axillary line. The two robotic arm ports should be symmetrical with a line that connects the camera port and the tumor. Usually, one arm is at the third intercostal space close to mid-axillary line, and the other arm is at the fifth intercostal space at the mid-clavicular line. The camera port and robotic arms should be in a section of arc, adjusted to the patient's figure (Figure 1). The right arm carries a permanent cautery hook that has an electrocautery function to perform resection. The left arm has Cadiere forceps (EndoWrist; Intuitive Surgical) to grasp the lesion. When the lesion is resected, the assistant then enlarges the robotic arm port incision to remove the specimen. The video shows robotic-assisted anterior mediastinal tumor resection (Figure 2).

\section{Posterior mediastinal lesion}

Patients with a posterior mediastinal lesion are placed with a contralateral decubitus position. The camera port is usually placed at the seventh intercostal space on the posterior axillary line. The robotic arm ports are usually at the sixth intercostal space on the anterior-axillary line and at the eighth intercostal space on the infrascapular line, with a distance of 7-8 $\mathrm{cm}$ from the camera port. Normally, we make an assistant incision in the fourth intercostal space on the anterior-axillary line to help expose the surgical field and remove the specimen.

\section{Follow-up}

The post-operative complications occurring within 30 days of surgery are evaluated according to the Clavien-Dindo classification (7). During the first year after surgery, the follow-up includes an enhanced chest CT scan every three months, every 6 months in the second year, and then once a year. For those patients with malignant tumors, we also recommend adjuvant chemotherapy or radiotherapy. 
Table 1 Patient characteristics

\begin{tabular}{|c|c|}
\hline General condition & Number of patients (\%) \\
\hline \multicolumn{2}{|l|}{ Gender } \\
\hline Male & $100(59.9)$ \\
\hline Female & $67(40.1)$ \\
\hline \multicolumn{2}{|l|}{ Comorbidities } \\
\hline MG & $18(10.8)$ \\
\hline Hypertension & $20(12.0)$ \\
\hline Diabetes mellitus & $7(4.2)$ \\
\hline COPD & $3(1.8)$ \\
\hline Coronary artery disease & $1(0.6)$ \\
\hline Chronic kidney disease & $2(1.2)$ \\
\hline Previous liver cancer & $1(0.6)$ \\
\hline Previous stomach cancer & $1(0.6)$ \\
\hline Others & $4(2.4)$ \\
\hline \multicolumn{2}{|l|}{ ASA } \\
\hline I & $48(28.7)$ \\
\hline II & $111(66.5)$ \\
\hline III & $8(4.8)$ \\
\hline \multicolumn{2}{|l|}{ BMI } \\
\hline$<18.5$ & $8(4.8)$ \\
\hline $18.5-24.5$ & $95(56.9)$ \\
\hline $24.5-30.0$ & $58(34.7)$ \\
\hline$>30.0$ & $6(3.6)$ \\
\hline \multicolumn{2}{|l|}{ Smoking (pack·year) } \\
\hline 0 & $139(83.2)$ \\
\hline $0-10$ & $7(4.2)$ \\
\hline $10-30$ & $10(6.0)$ \\
\hline $30-50$ & $11(6.6)$ \\
\hline \multicolumn{2}{|l|}{ FEV1\% } \\
\hline $50-75$ & $6(3.6)$ \\
\hline $75-100$ & $83(49.7)$ \\
\hline$>100$ & $78(46.7)$ \\
\hline
\end{tabular}

\section{Results}

\section{General data}

There were 167 patients, namely, 67 females and 100 males, with a mean age of 50.2 years (range, 12-78 years). The general data for the patients are shown in Table 1. The mean in-hospital cost was $¥ 64,563 \pm ¥ 10,899.67$.

\section{Surgical data and perioperative data}

Complete resections were achieved in 164 cases, except for one case of squamous cell cancer of the thymus and two cases of angioma. The mean operation time and docking time are $70.01 \pm 29.49$ and $10.12 \pm 2.77 \mathrm{~min}$, respectively, with a mean blood loss of $60.34 \pm 115.38 \mathrm{~mL}$. We analyzed the times of the first twenty, second twenty and last twenty mediastinal lesion resections as well as the docking time, as shown in Table 2. A significant difference in the operation time was observed between the first twenty operations and the last twenty operations. However, the operation times for the second twenty operations presented no significant difference with those of the last twenty operations. The learning curve is presented in Figure 3. Three cases $(1.8 \%)$ were converted to sternotomy because of massive blood loss (>600 mL) in two cases and because of severe pleural adhesion in one case. The mean drainage on the first day after operation was $122.83 \pm 107.58 \mathrm{~mL}$, and the mean drainage duration was 2.95 days, with a range of 1-7 days.

There was no intra- or perioperative death in these 167 patients. Grade II complications (according to the Clavien-Dindo classification) occurred in 5 (3\%) patients. Two patients had atrial fibrillation and needed medical intervention. Three patients had high fever $\left(>38.5^{\circ} \mathrm{C}\right)$ after being discharged from the hospital and needed pharmacologic treatment.

\section{Pathologic data}

There were 56 thymomas, 52 cysts, 17 schwannomas, 9 bronchogenic cysts, 6 thymic hyperplasias, 6 foregut cysts, 4 squamous carcinomas, 3 teratomas, 2 neurofibromas, 2 angiomas, 2 epidermoid cysts, 2 thymic carcinoids, 1 pericardial cyst, 1 tracheoesophageal cyst, 1 ganglioneuroma, 1 sarcoidosis, 1 giant lymph node hyperplasia and 1 calcified pleural nodule. The average diameter of the mediastinal lesions was $3.85 \mathrm{~cm}$, with a range of 0.40 to $10.00 \mathrm{~cm}$. In total, 56 thymomas were classified according to the WHO and staged according to 
Table 2 Comparison of docking and operative time between early and later period

\begin{tabular}{lccccc}
\hline \multirow{2}{*}{ Procedures } & First twenty & Second twenty & Last twenty & \multicolumn{2}{c}{ P value } \\
\cline { 5 - 6 } & & & First twenty vs. last twenty & Second twenty vs. last twenty \\
\hline Operation time (min) & $116.5 \pm 35.84$ & $69.20 \pm 24.87$ & $71.15 \pm 22.01$ & $<0.001$ & 0.79 \\
Docking time (min) & $16.10 \pm 3.78$ & $10.60 \pm 1.85$ & $9.60 \pm 0.75$ & $<0.001$ & 0.03 \\
\hline
\end{tabular}

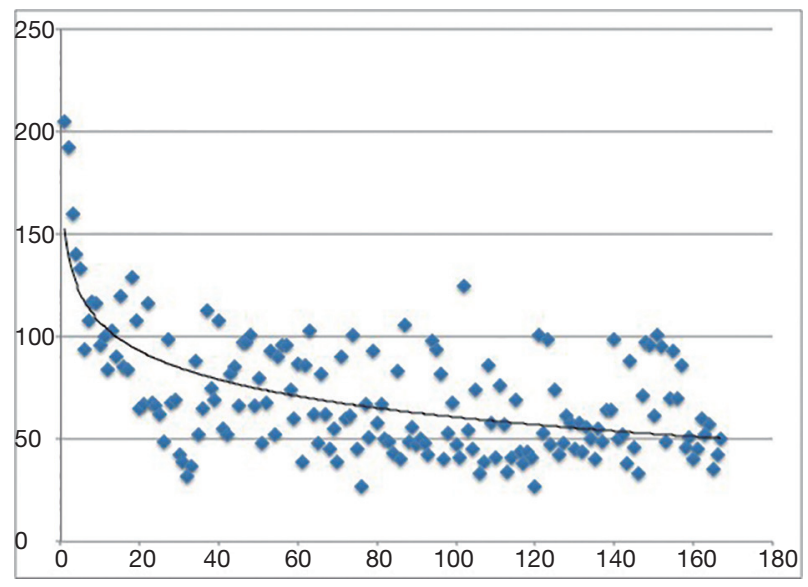

Figure 3 Learning curve (horizontal axis: case number; vertical axis: operation time/min).

Table 3 WHO histologic typing of resected thymoma

\begin{tabular}{lc}
\hline WHO histologic type & Number \\
\hline Micronodular thymoma & 3 \\
A & 4 \\
AB & 25 \\
B1 & 13 \\
B2 & 6 \\
B3 & 5 \\
\hline
\end{tabular}

Masaoka, as presented in Tables 3,4.

\section{Follow-up}

The follow-up period ranged from 2-99 months, with a median follow-up of 28 months. MG symptoms were improved in all $18(100 \%)$ patients who complained about myasthenia before the surgery. Adjuvant chemo/ radiotherapy was recommended for patients diagnosed with Masaoka stages II and III. Among the 56 patients who underwent robotic thymectomies, five patients presented
Table 4 Masaoka staging of resected thymoma

\begin{tabular}{lc}
\hline Masaoka stage & Number \\
\hline I & 5 \\
IIA & 23 \\
IIB & 16 \\
III & 12 \\
\hline
\end{tabular}

radiological evidence of recurrence: three patients underwent a second operation, while the other two had distant metastasis. One patient died due to progression of squamous cell cancer of the thymus.

\section{Discussion}

The robotic surgical system has greatly progressed in China in recent years, and it has unique advantages in posterior mediastinal lesion resection compared to open surgery and VATS (8). The robotic surgical system can provide a highdefinition three-dimensional vision, interactive robotic arms with an EndoWrist system, a tremor filter and a conventional monitor console. Mediastinal lesions (including thymoma, thymic carcinoma, cyst, teratoma, and neurogenic tumor), especially anterior mediastinal mass, is the best indication for robotic surgery (9-11). There have been several studies comparing robotic mediastinal lesion resection to sternotomy and to VATS. Robotic mediastinal operation allows complete resection of mediastinal lesion and can reduce the incidence of post-operative complications and blood loss during the surgery with satisfactory long-term outcomes.

These 167 consecutive cases for a group of heterogeneous patients represent the largest experience of robotic mediastinal lesion resection in China and produced perioperative and long-term outcomes consistent with those of other recent reports $(2,3,5,12)$. From our experiences, the position of the ports is of great importance to ensure complete resection of the lesion and access to the entire 
mediastinal space, especially for an anterior mediastinal mass. In anterior mediastinal lesion resection, the camera port should point to the mass at an angle of $45^{\circ}$ to the anterior midline. The enhanced chest CT scan should be assessed before surgery by 1-2 experienced thoracic surgeons to evaluate the lesion and surrounding tissue. After 20 procedures, a surgeon can obtain a basic understanding of robotic-assisted mediastinal surgery.

At present, patients must pay extra money to undergo robotic surgery, which is not covered by medical insurance. This may explain the lower popularity of robotic surgery in China than in America.

Previous studies and our retrospective study have demonstrated that robotic-assisted mediastinal lesion surgery is safe and effective. Further prospective RCT studies are needed to verify the effectiveness and safety of robotic surgical systems.

\section{Acknowledgements}

Funding: This work was supported by Shanghai Hospital Development Center (Grant Number: SHDC12016113).

\section{Footnote}

Conflicts of Interest: The authors have no conflicts of interest to declare.

Ethical Statement: This study was approved by the ethics board of Shanghai Chest Hospital (KS(P)1805).

\section{References}

1. Melfi FM, Menconi GF, Mariani AM, et al. Early experience with robotic technology for thoracoscopic surgery. Eur J Cardiothorac Surg 2002;21:864.

Cite this article as: Li H, Li J, Huang J, Yang Y, Luo Q. Robotic-assisted mediastinal surgery: the first Chinese series of 167 consecutive cases. J Thorac Dis 2018;10(5):2876-2880. doi: 10.21037/jtd.2018.04.138
2. Rea F, Schiavon M, Di CF, et al. Single-institution experience on robot-assisted thoracoscopic operations for mediastinal diseases. Innovations 2011;6:316-22.

3. Melfi F, Fanucchi O, Davini F, et al. Ten-year experience of mediastinal robotic surgery in a single referral centre. Eur J Cardiothorac Surg 2012;41:847-51.

4. Weksler B, Tavares J, Newhook TE, et al. Robot-assisted thymectomy is superior to transsternal thymectomy. Surg Endosc 2012;26:261-6.

5. Seong YW, Kang CH, Choi JW, et al. Early clinical outcomes of robot-assisted surgery for anterior mediastinal mass: its superiority over a conventional sternotomy approach evaluated by propensity score matching. Eur J Cardiothorac Surg 2014;45:e68-73; discussion e73.

6. Li H, Li J, Huang J, et al. Robotic-assisted anterior mediastinal tumor resection. Asvide 2018;5:522. Available online: http://www.asvide.com/article/view/24995

7. Seely AJE, Ivanovic J, Threader J, et al. Systematic Classification of Morbidity and Mortality After Thoracic Surgery. Ann Thorac Surg 2010;90:936-42.

8. Kajiwara N, Kakihana M, Usuda J, et al. Extended indications for robotic surgery for posterior mediastinal tumors. Asian Cardiovasc Thorac Ann 2012;20:308-13.

9. DeRose JJ Jr, Swistel DG, Safavi A, et al. Mediastinal mass evaluation using advanced robotic techniques. Ann Thorac Surg 2003;75:571-3.

10. Bodner J, Wykypiel H, Greiner A, et al. Early experience with robot-assisted surgery for mediastinal masses. Ann Thorac Surg 2004;78:259-65.

11. Savitt MA, Gao G, Furnary AP, et al. Application of robotic-assisted techniques to the surgical evaluation and treatment of the anterior mediastinum. Ann Thorac Surg 2005;79:450-5.

12. Rueckert J, Swierzy M, Badakhshi H, et al. Roboticassisted thymectomy: surgical procedure and results. Thorac Cardiovasc Surg 2015;63:194-200. 